\title{
Markers of pregnancy: how early can we detect pregnancies in cattle using pregnancy-associated glycoproteins (PAGs) and microRNAs?
}

\author{
S.T. Reese ${ }^{1}$, M.C. Pereira ${ }^{2}$, J.L.M. Vasconcelos ${ }^{2}$, M.F. Smith ${ }^{3}$, J.A. Green ${ }^{3}$, T.W. Geary ${ }^{4}$, R.F.G. Peres ${ }^{2}$, \\ G.A. Perry ${ }^{5}$, K.G. Pohler ${ }^{1,6}$ \\ ${ }^{1}$ Department of Animal Science, University of Tennessee, Knoxville, TN. \\ ${ }^{2}$ Departamento de Produção Animal, Faculdade de Medicina Veterinária e Zootecnia-UNESP, Botucatu, Brazil. \\ ${ }^{3}$ Division of Animal Science, University of Missouri, Columbia, MO. \\ ${ }^{4}$ USDA-ARS, Fort Keogh Livestock and Range Research Laboratory, Miles City, MT. \\ ${ }^{5}$ Department of Animal Science, South Dakota State University, Brookings, SD.
}

\begin{abstract}
Pregnancy detection has evolved over the last few decades and the importance of early pregnancy detection is critical to minimize the amount of time a cow spends not pregnant. Embryonic mortality (EM) is generally considered to be the primary factor limiting pregnancy rates in cattle and occurs early (<day 28$)$ or late $(2$ day 28$)$ during gestation (day $0=$ estrus). In cattle, the incidence of early EM is approximately 20 to $40 \%$ and the incidence of late EM is approximately 3.2 to $42.7 \%$. Significant effort has been directed toward understanding the mechanisms resulting in early EM up to day 17; however, relatively little is known about the causes or mechanisms associated with EM after day 17. Based on work in these areas, numerous investigators are pursuing methods of early pregnancy or EM detection after day 17 of gestation. This review will highlight some of the technology and markers being used for early pregnancy detection and provide evidence for just how early pregnancy can be detected in the bovine. Advancements in early embryonic or pregnancy detection may lead to development of strategies to overcome early gestation losses.
\end{abstract}

Keywords: cattle, embryonic mortality, placenta, pregnancy.

\section{Introduction}

Successful pregnancy is the most important factor to ensure an efficient and economically sound beef or dairy operation. In order to reach that end point, reproductive loss must be avoided. Early identification of pregnancy failure is key to determining the most effective management strategies and the ability to predict this loss offers greater opportunity to minimize its impact. Loss of pregnancy may occur at any time between conception and calving; however, some time points are more critical than others. Pregnancy failure affects all cattle; however, high producing dairy cattle are more susceptible to decreased pregnancy rates than dairy heifers and beef cows (Diskin et al., 2011; Pohler et al., 2015a; Pohler et al., 2016a, b). Although fertilization rate in cattle is often greater than $85 \%$ (Santos et al., 2004, Diskin and Morris, 2008) there have been reports of differences in fertilization rates in beef and dairy cattle that result in a large amount of reproductive failure (Breuel et al., 1993, Sartori et al., 2002; Santos et al., 2004, 2009); however, the focus of this review will be on post fertilization failure and detection. In addition, fetal losses (>day 45 of gestation) are low at approximately 3\% (Inskeep and Dailey, 2005). Thus, reproductive loss during the embryo stage (day 0 to 44 ) of development is substantial. Early embryonic loss can be classified as loss that occurs before day 28 of gestation. Although the embryonic heartbeat can be detected by this time via real-time ultrasonography, the conceptus does not yet resemble a calf. Causes of early embryonic mortality include lethal genetic mutations, uterine asynchrony, and maternal recognition failure (Ayalon, 1978; Diskin and Morris, 2008). Early embryonic loss is generally accepted to account for 20 to $40 \%$ of pregnancy failure (Sreenan and Diskin, 1986; Inskeep and Dailey, 2005; Santos et al., 2004, 2009). During the late embryonic period, through day 44 , growth can be characterized by the development of limb buds, eye orbits and the formation of placentomes. Although late embryo mortality accounts for less than $10 \%$ of pregnancy loss, it has significant implications for the producer and has been suggested to cause greater financial burden then early EM (Diskin and Morris, 2008). By day 45, the conceptus takes the true form of a fetus with split hooves, ribs and displays limited movement (Curran et al., 1986). After days 45 to 60 pregnancy loss decreases and is less than 5\% through the second and third trimester of pregnancy.

Pregnancy failure is extremely costly to the producer. Lost revenue can be attributed to cost of feeding and managing nonpregnant cows, decreased weight of late born calves at sale time and a decreased calving percentage due to cows that lost pregnancy. In a study involving lactating dairy cows, pregnancy loss after 1 month of gestation cost producers an average of $\$ 555$ (US) due to repeat breeding expenses, increased calving interval and increased probability of involuntary culling (De Vries, 2006). In beef cattle that have had pregnancy loss and manage to become pregnant to a subsequent breeding, there is still a significant amount of lost revenue from reduced weight of late born calves and decreased uniformity of the calf crop. Pregnancy diagnosis is a very important management tool that is underutilized in the United States. According to the USDA's 2008 National Animal Health Monitoring System (NAHMS) Beef survey, only $20 \%$ of operations 
utilize pregnancy diagnosis via palpation or ultrasound, a number that has remained virtually unchanged since the 1997 survey (United States Department of Agriculture - USDA, 2010). In comparison, the 2007 NAHMS Dairy survey reported $93 \%$ of operations perform pregnancy detection (USDA, 2009). Pregnancy diagnosis can identify open cows, help estimate calving dates, and help producers make culling decisions. This review will describe various methods of pregnancy diagnosis in cattle and research advancements that may allow for earlier detection of pregnancy.

\section{Established methods of pregnancy diagnosis}

\section{Rectal palpation and ultrasonography}

As the conceptus develops during gestation, fluid accumulates, and placentation advances, methods of pregnancy detection allow for manual transrectal palpation of the uterus per rectum and its contents. Transrectal palpation of the uterus, starting as early as day 35 of gestation allows for detection of a pregnancy by palpation of fluid and the amniotic vesicle within the uterus. Palpation of the uterus and its contents is traditionally practiced from 40 to 60 days after insemination with the earliest detection limit being approximately 30 to 35 days post insemination. Additional sensitivity can be achieved during this time point by using transrectal ultrasound for pregnancy detection (Lucy et al., 2011). Ultrasound is the gold standard for determining pregnancy and confirming the presence of a viable embryo. Transrectal ultrasonography can be accurate as early as day 26 to 29 to diagnose pregnancy and visualize a discernable heartbeat (Pierson and Ginther, 1984; Kastelic et al., 1988; Beal et al., 1992). Doppler ultrasound may provide additional information based on visualization of blood flow to the placenta/conceptus; however, data supporting its use as a pregnancy diagnosis method has been mixed. Today, ultrasound is considered the only visual indicator of pregnancy in cattle and is used for comparison with all recent attempts at diagnosing earlier pregnancy in this review. With all palpation and ultrasound techniques, a highly experienced individual is required to complete these test.

\section{Chemical based pregnancy tests}

Earlier and more effective means of pregnancy diagnosis are constantly being sought and evaluated. Numerous chemical and biochemical based pregnancy tests have been developed and tested for use in cattle Each has strengths and shortcomings that have led to their adoption or lack of use in various production schemes. One important consideration in evaluating pregnancy diagnosis tests is the difference between pregnancy specific and non-pregnancy specific methods. Pregnancy specific markers are physiologically present only in pregnant animals and produced specifically from the pregnancy; whereas nonpregnancy specific markers, while elevated during pregnancy, may be produced under other physiological conditions as well.

Progesterone is one example of a nonpregnancy specific diagnosis method. Progesterone is one of the more common chemical based pregnancy tests commercially available although overall a very small percentage of producers use it (USDA, 2009). Produced by the corpus luteum (CL), progesterone is a steroid hormone that is crucial for maintaining pregnancy; however, the cyclic profile of progesterone mandates that pregnancy detection must occur between luteolysis and the formation of a new CL. During this time period, non-pregnant cows should exhibit low progesterone levels, whereas progesterone concentrations in pregnant cows should remain elevated. Significant differences in progesterone concentration appear between pregnant and nonpregnant cows between day 20-24 post insemination in both serum and milk. Accurate positive pregnancy diagnosis varied between 60 and $100 \%$ for milk progesterone, however detection of non-pregnant animals varied between 81 to $100 \%$ (Nebel et al., 1987; Sasser, 1987, Nebel, 1988). Longer luteal phases in some cows, cysts or persistent follicles may play a role in elevated progesterone concentrations during the pregnancy test period that yield false positive results (Pohler et al., 2015a). Some discrepancies exist in evaluating the effectiveness of progesterone testing with regards to embryo loss. Research has shown that pregnant cows with progesterone concentration below $3.76 \mathrm{ng} / \mathrm{ml}$ at week 5 were more likely to experience embryonic mortality before week 9 than cows with a greater concentration of progesterone (Starbuck et al., 2004). However, it should be noted that a majority of cows $(77 \%)$ in the low concentration group maintained pregnancy through week 9 . A later study by Pohler et al. (2013), demonstrated that serum concentration of progesterone between day 28 to 30 in pregnant cows was not predictive of pregnancy loss between a positive pregnancy diagnosis by progesterone and final pregnancy confirmation at day 70 of gestation.

Another steroid hormone, estrone sulfate is produced by the conceptus and can be detected at day 100 of pregnancy in cattle (Holdsworth et al., 1982). Estrone sulfate is a pregnancy specific marker, though its late period of detection limits its use in domestic cattle. Although steroid hormone pregnancy tests have largely been replaced in cattle, sheep and swine, use of estrone sulfate has been used for pregnancy detection of non-domestic animals in the wild and zoos through noninvasive fecal and urine samples. Estrone sulfate has been successfully evaluated for use in pregnancy detection in hoofed stock, gorillas, orangutans, baboons and wild felids (Kumar et al., 2013).

Early pregnancy factor (EPF), also known as early conception factor, appears in maternal circulation shortly after fertilization. In cattle, EPF is observed within $48 \mathrm{~h}$ after breeding and seems to contribute to maternal immune suppression and implantation preparation (Morton, 1998; Cordoba et al., 2001). A study by Athanasas-Platsis, et al. (1989) demonstrated a critical role of EPF when mice that had been immunized against EPF had decreased embryo viability and an 
increased incidence of pregnancy failure. Action of EPF is not confined to pregnancy as growth factor-like properties have been seen in tumors. A large percentage of embryo loss occurs after the recommended sampling time of commercial EPF assays (48 $\mathrm{h}$ to 7 days). Studies have indicated that commercial EPF tests have a sensitivity (or detection of pregnant animals) of 45 to $86 \%$ and a specificity (or detection of non-pregnant animals) of 4 to $28.8 \%$ (Cordoba et al., 2001; Gandy et $a l ., 2001)$. In regards to EPF as a pregnancy detection method, commercial tests are unreliable at identifying non-pregnant animals that limits its use in this capacity.

The maternal recognition of pregnancy signal in cattle and other ruminants is interferon tau (IFNT). Interferon tau stimulates $\mathrm{CL}$ maintenance through endocrine-like actions, blocks estrogen receptors and paracrine mechanisms on the endometrium prompt IFNT stimulated gene production (Pohler et al., 2015a, Spencer and Hansen, 2015). Due to the difficulty associated with detecting small concentrations of IFNT directly, research has focused on measuring IFNTstimulated genes (ISGs) that have been upregulated in peripheral mononuclear blood cells (PBL). Conceptus IFNT mRNA concentration peaks in cattle at day 20 post-conception (Han et al., 2006; Spencer and Hansen, 2015). Genes including ISG15, Mx 1 and $M x 2$ are more highly expressed in peripheral blood leukocytes (PBL) of pregnant cows than non-pregnant cows (Han et al., 2006; Gifford et al., 2007). A study by Green, et al. (2010), showed that pregnant heifers had greater IFNTstimulated gene expression than cows. They concluded that a IFNT-stimulated gene based pregnancy test would be possible for heifers at day 18 but not for cows whose response is more limited based on the current sensitivity of available assays (Green et al., 2010). Unfortunately, ISGs are not unique to pregnancy which limits their use as a pregnancy detection tool to identifying nonpregnant animals (Han et al., 2006; Gifford et al., 2007; Pohler et al., 2015a); however, a resynchronization protocol can be implemented in cows that are identified as non-pregnant which improves operation efficiency (Lucy et al., 2011).

\section{MiRNAs: potential biomarkers for pregnancy diagnosis}

The search for easily accessible biomarkers of various diseases and physiological states has recently focused on circulating microRNAs (miRNA). Between 18 and 22 nucleotides in length, miRNAs play important roles in regulation of gene expression and have been found in biological fluids ranging from serum and amniotic fluid to urine and milk (Reid et al., 2011; Pohler et al., 2015a). MicroRNAs are released from cells of most tissue types in plasma membrane bound extracellular vesicles (EV), especially exosomes. The packaging of miRNA in EVs or exosomes is important from a detection standpoint as RNA-ases are unable to penetrate and breakdown the miRNA allowing them to be extracted from blood and serum (Reid et al., 2011). Exosomes and EVs play a crucial role in intercellular communication, including promotion of sperm maturation, regulation of immune function, release of miRNA for a wide array of regulatory functions, as well as other roles currently being studied (Raposo and Stoorvogel, 2013). Serum and whole blood have proved an acceptable source of EV-derived miRNA profiles, thus providing a potential blood-borne biomarker candidate for various disease and physiological states (Häusler et al., 2010; Reid et al., 2011). Human based disease research has revealed significant differences in miRNA abundance for many cancers (Lawrie et al., 2008; Häusler et al., 2010), heart disease (Tijsen et al., 2010) and sepsis (Wang et al., 2010). In addition, circulating miRNAs in maternal serum have been observed as potential biomarkers of pregnancy status due to their significant impact on gene expression and regulation (Chim et al., 2008). A study by Gilad et al. (2008) identified miRNAs that are increased in abundance in pregnant humans but not in non-pregnant females. This finding led to the rapid expansion of identifying miRNAs that were specific to pregnancy and across various species, although none have been thoroughly explained.

An initial study of pregnancy specific markers in mares identified 7 miRNAs that were only expressed in pregnant mares (Cameron et al., 2011) compared with the non-pregnant controls. In addition, work in the sheep has confirmed the presence of miRNA in uterine lumen fluid in pregnant and cyclic sheep (Burns et al., 2014). These data support the idea for a likely role of miRNA in conceptus-endometrial interactions during the establishment of pregnancy (Burns et al., 2014). In addition, a follow up study to the one described above, provides evidence that EVs are produced from the trophectoderm and uterine epithelia in the pregnant ewe and are involved in intercellular communication (Burns et al., 2016).

Many groups are now looking into miRNAs as biomarkers for pregnancy detection in the cow. There is increasing evidence that pregnancy specific miRNAs exist and may be potential markers for pregnancy diagnosis. In 2015, exosomal miRNAs were reported to be differentially expressed in pregnant versus nonpregnant cows and cows undergoing early embryonic mortality (Pohler et al., 2015b). A recent study by Fiandanese et al. (2016) identified a potential miRNA, bta-mir 140, as an early biomarker for pregnancy detection. At day 19, bta-mir 140 was up regulated in all pregnant cows, and at day 13 onwards, it was upregulated in pregnant, non-lactating cows (Fiandanese et al., 2016). Similarly, Ioannidis and Donadeu (2016) identified 6 miRNA (day 16: bta-miR-26a, bta-miR-29c, bta-miR138, bta-miR-204. Day 24: bta-miR-1249, day 16 \& 24: hsa-miR-4532) that were differentially expressed in pregnant heifers. Although refinement is necessary to pinpoint ideal miRNA for pregnancy diagnosis, results indicate that miRNAs have potential as an early pregnancy detection tool. Furthermore, miRNA may provide information to denote embryonic viability. Preliminary data from our laboratory indicate cows that experience embryo mortality compared to cows that have a successful pregnancy have a significantly increased abundance of specific miRNAs at days 17 and 24 of 
gestation. Future studies are needed to assess the repeatability of these findings and to determine precise miRNA most applicable for embryo viability analysis.

\section{Developing early pregnancy diagnosis method; pregnancy associated glycoproteins}

\section{The placenta}

Proper placentation is crucial for pregnancy development and ultimately pregnancy success. Active placentation in the cow occurs between day 28 and 40 of gestation (Aires et al., 2014). Bovine placentation involves adhesion between the maternal-caruncle structures and fetal cotyledonary tissues to form placentomes. Superficial interdigitation begins around day 20 in cattle between microvilli of the trophectoderm and uterine epithelium. True placentomes, marked by increased villi length and raised tissue in caruncular endometrium are distinct by days 31 to 33 of gestation. By day 39 , placentomes are easily discernable and have long, occasionally branching villi (King et al., 1979).

Binucleated trophoblast cells (BNCs) appear in the fetal chorion of ruminants at days 18 to 19 of gestation and comprise 15 to $20 \%$ of the trophectoderm throughout pregnancy. Binucleated trophoblast cells migrate to the maternal epithelium from the fetal chorion after maturation but do not penetrate past the basement membrane (King and Atkinson, 1987). Contact between the maternal and fetal interface at the microvilli junction allows migration of BNC's towards the basement membrane to begin (Wooding and Wathes, 1980, Wooding and Burton, 2008). Products of BNC's, including hormones, placental lactogen and pregnancy associated glycoproteins (PAGs), are packaged in secretory granules and enter maternal circulation across the basement membrane (Pohler et al., 2015a).

\section{PAG production}

Pregnancy associated glycoproteins were identified in the 1980's during early attempts to develop pregnancy-specific markers that could be used for pregnancy diagnosis. Although PAGs are often thought of to be produced by BNCs, Green et al. (2000) reported that PAGs can be sorted into two separate families based on their expression in trophoblast cells. Some PAGs are expressed in both BNCs and mononucleated trophoblast cells while others are solely produced in BNCs (Green et al., 2000). Although their physiological role is unknown, a large number of distinct PAGs and more than two dozen specific PAG genes have been described. Based on accumulation of PAGs at the junction between uterus and placenta and known proteolytic activity of certain PAGs, it has been hypothesized that PAGs may help process growth factors or may have adhesion actions (Wallace et al., 2015). Based on evidence that PAGs may inhibit certain immune cells, they may also play a role in disguising antigens from the maternal immune system (Perry et al., 2005). After appearance of BNCs and epithelial adhesion of trophoblast, the first sizable increase in
PAG concentration occurs between days 22 to 24 of gestation. Concentrations of PAG continue to increase through day 36 , followed by subsequent decrease in concentration until day 60 of pregnancy followed by a steady increase through the second and third trimesters of pregnancy. In the weeks preceding parturition, a substantial increase in circulating concentrations of PAG occurs that peaks at calving. This may be attributed to significant placental growth at the end of gestation or the release of stored PAG from other tissues (Green et al., 2005; Pohler et al., 2013). Eight weeks post parturition, PAGs are not detectable in maternal circulation (Green et al., 2005).

\section{PAGs and pregnancy diagnosis}

Since their discovery, PAGs have been a target for pregnancy diagnosis. Pregnancy-specific protein B was the first identified PAG of interest by scientists looking for pregnancy specific markers that could be detected early in gestation in the 1980's (Butler et al., 1982; Sasser et al., 1986). Using early assays, PAGs were detectable at day 24 of gestation in cattle; however, the physiological function was unknown which is still the case today. Discovery of multiple PAG families and genes has contributed to understanding the increasing complexity of PAGs. The radioimmunoassay (RIA) first developed shortly after discovery of pregnancy specific protein B was the standard for PAG detection for many years (Zoli et al., 1992). This assay was highly specific and the validating study concluded that PAGs were secreted into the maternal system and were unique to pregnant animals. A study by Green et al. (2005) validated an ELISA that specifically targeted PAGs secreted early in gestation that had a shorter halflife (4.3 days vs. 8.4 days) than the previous targets to reduce the potential for false positives in postpartum cows (Zoli et al., 1992; Sousa et al., 2003; Green et al., 2005). The ELISA was demonstrated to accurately detect pregnant cows via serum concentrations of PAGs at day 28 post insemination. Studies comparing the efficacy of the PAG ELISA, PAG RIA and transrectal ultrasonography revealed comparable results for the diagnosis of pregnancy in cattle at day 28 of gestation although some differences were identified in the ability of certain assays to detect non-pregnant animals (Szenci et al., 1998; Karen et al., 2015).

Commercial PAG tests are currently available using both milk and blood samples, and include BioPRYN (BioTracking LLC. Moscow, ID USA), IDEXX Bovine pregnancy test (IDEXX Laboratories Inc. Westbrook, ME USA) and DG29 pregnancy test (Genex Cooperative Inc. Shawano, WI USA). BioPRYN accepts blood samples from heifers 25 days post breeding and cows 28 days post breeding, IDEXX recommends day 28 blood or milk samples and DG29 has been validated using day 29 blood samples. At the recommended sampling time, all commercial tests provide $98-99 \%$ true positive (pregnant) reading and false positive (reported as pregnant but open) rates range from $1-5 \%$ however, some variation may be due to late embryonic mortality. 


\section{Early pregnancy diagnosis}

Current research is focused on finding markers and increasing sensitivity to identify pregnant cows before day 28 of gestation. Although diagnosis is limited to the time frame following the introduction of PAGs to maternal circulation at days 19 to 20, preliminary research indicates that PAGs may be effective at diagnosing pregnancy as early as day 24 . Currently, research is focused on heifers, which exhibit greater PAG concentrations earlier in gestation compared with cows. A recent study in Brazil evaluated the accuracy of pregnancy diagnosis at day 24 in predominantly Holstein heifers following timed embryo transfer (Reese et al., 2016). Serum PAG concentrations at day 24 differed between pregnant $(2.98 \mathrm{ng} / \mathrm{ml})$ and non-pregnant $(0.69 \mathrm{ng} / \mathrm{ml})$ heifers. Using receiver operating curve analysis, PAG concentrations greater than $1.39 \mathrm{ng} / \mathrm{ml}$ were $95 \%$ accurate in diagnosing a pregnant heifer at day 24 of gestation. Using a day 17 baseline sample, the difference between day 24 and day 17 samples predicted $79 \%$ of pregnancies. This, early pregnancy diagnosis using PAG is possible; however, more work is needed in this area. It is realistic to assume that day 24 PAG concentrations can diagnosis pregnancy, but high rates embryonic loss before the standard day 30 tests may decrease the efficiency and benefits of testing early. In a recent study, embryonic mortality between day 24 and 31 of gestation was $20.8 \%$ in lactating dairy cows, thus pregnancy loss following maternal recognition of pregnancy may be more prevalent than previously thought making early pregnancy diagnosis less useful (Pohler et al., 2016a).

\section{PAGs as indicators of embryo success}

Recent studies have demonstrated a strong correlation between successful pregnancies and PAG concentrations during early gestation. Increased circulating PAG concentrations approximately day 28 of gestation are generally predictive of increased embryo survival, making PAG a likely marker for evaluating embryo viability and placental competence. In comparison to progesterone, which exhibit no difference between heifers or cows that undergo embryo mortality and those that maintain pregnancy, PAG concentrations are significantly different between heifers and cows (Fig. 1; Kill et al., 2013). Serum PAG concentrations in cows that maintained pregnancy $(4.53 \pm 0.34 \mathrm{ng} / \mathrm{ml})$ were significantly higher than cows that underwent pregnancy loss $(3.14 \pm 0.72 \mathrm{ng} / \mathrm{ml})$ after fetal heartbeat detection at day 28 (Pohler et al., 2013). All cows had a pregnancy with a fetal heartbeat at day 28 , indicating a viable pregnancy at that time. Perhaps more importantly, PAGs seem to be particularly effective at identifying cows that will undergo late embryonic or early fetal mortality. As serum concentrations increased, the probability of embryo mortality significantly decreased. Late embryo mortality between days 31 and 59 was predicted with $95 \%$ accuracy if PAG concentrations were $<1.4 \mathrm{ng} / \mathrm{ml}$ at day 31 after timed artificial insemination (Pohler et al., 2016a). Pohler et al. (2016b) demonstrated that both Bos indicus and Bos taurus cows that experienced embryo mortality had similar and lower PAG concentration at day 28 despite the significant differences between PAG concentrations of successful pregnancy in Bos taurus compared with Bos indicus cows (Fig. 2).

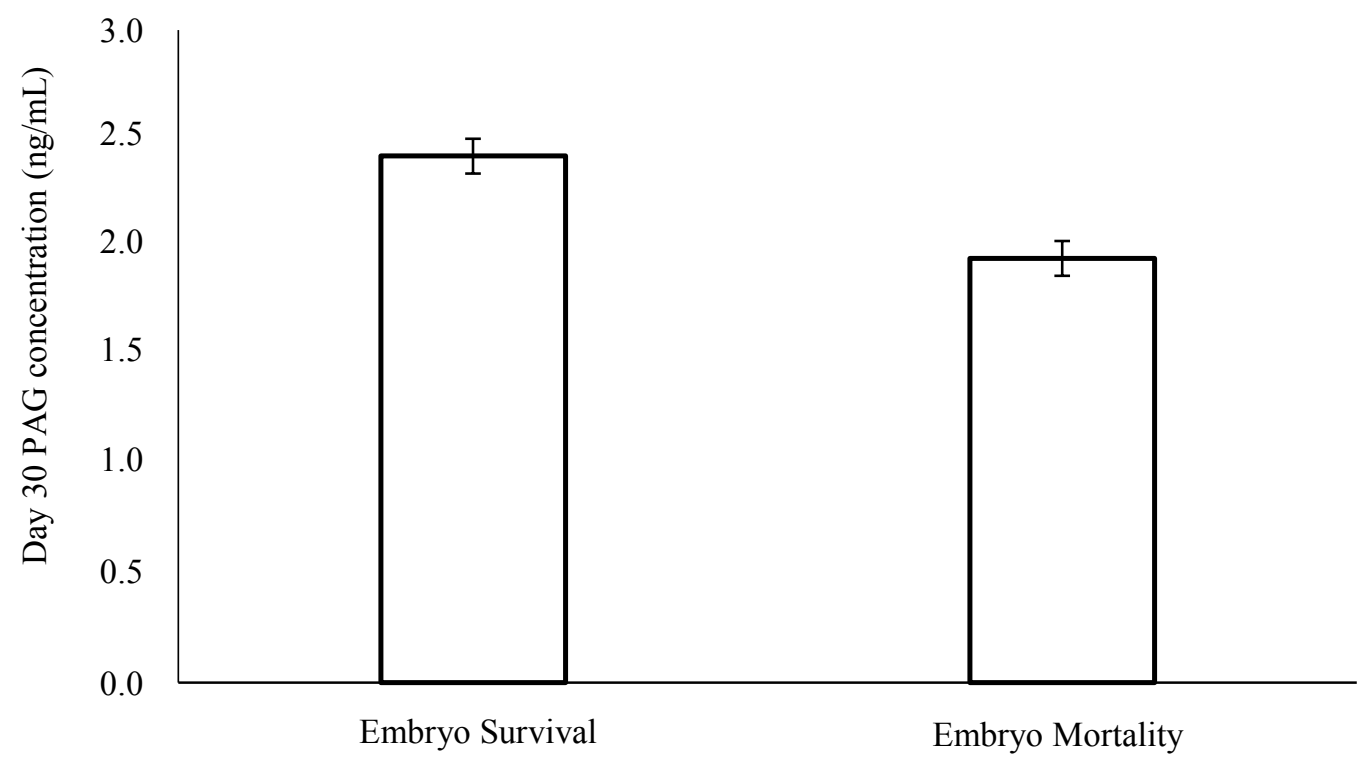

Figure 1. Serum concentrations of pregnancy-associated glycoproteins (PAGs) in heifers that had a embryonic heartbeat on day 30 and maintained pregnancy (Embryo survival; $n=406$ ) or did not maintain pregnancy (Embryo mortality; $n=21$ ). Heifers that had embryo mortality between gestation days 30 and 65 had significantly less PAG serum concentrations than heifers that maintained pregnancy. 


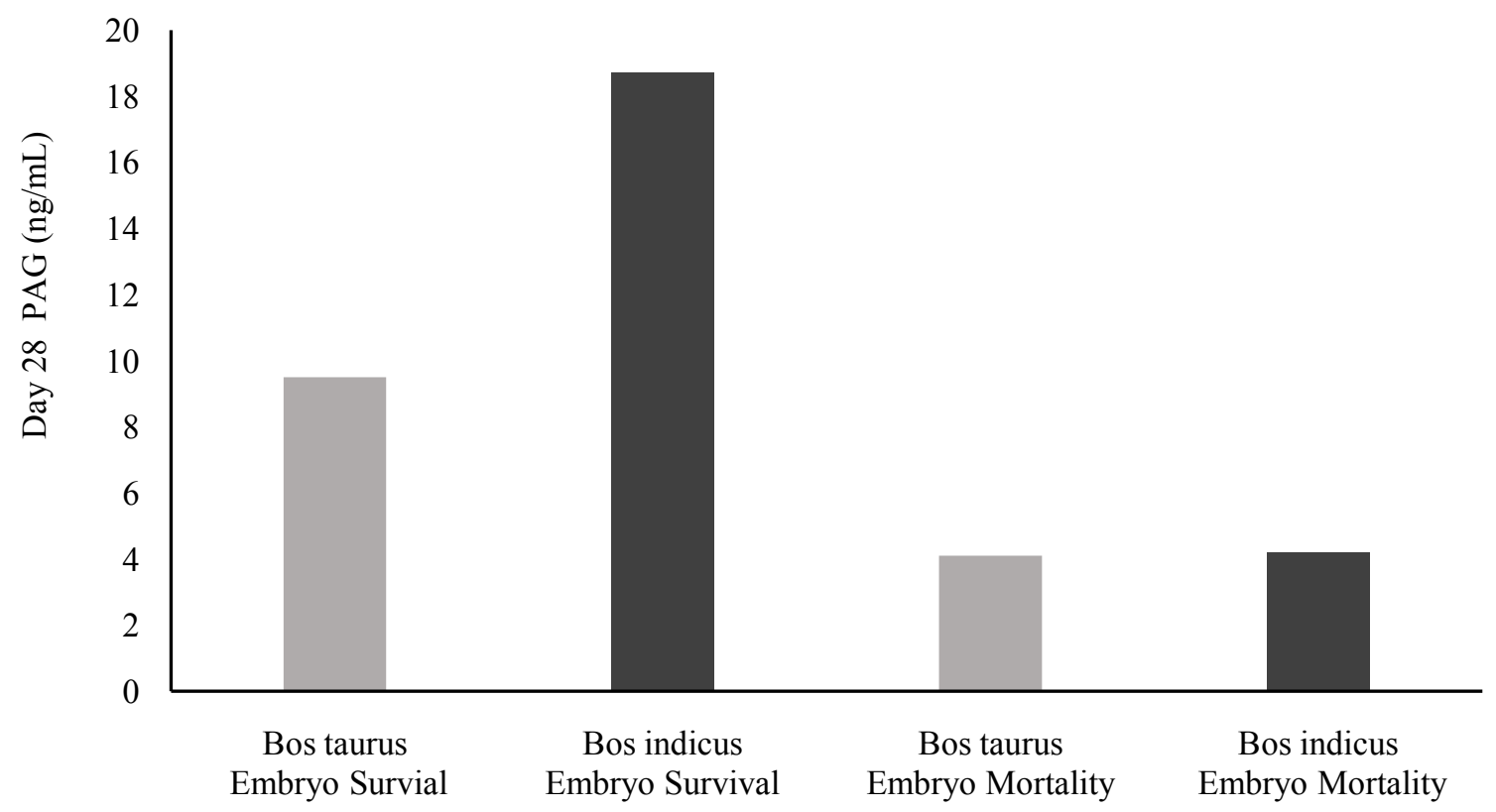

Figure 2. Serum concentrations of pregnancy-associated glycoproteins (PAGs) in samples collected on day 28 of gestation from pregnant Bos taurus cows and Bos indicus cows with a viable embryo based on fetal heartbeat. Cows were then categorized into whether they maintained pregnancy until day 72 (Bos Taurus; $\mathrm{n}=1416$ ) or day 100 (Bos indicus; $\mathrm{n}=1365$ ) of gestation (Embryonic survival) or embryonic mortality (between days 29 to 72 or 100; Bos Taurus; $\mathrm{n}=171$; Bos indicus; $\mathrm{n}=213)$. Beef cows that experienced late embryonic mortality had decreased $(\mathrm{P}<$ 0.05 ) circulating concentrations of PAGs on day 28 compared to cows that maintained an embryo.

A multitude of factors have may affect circulating PAG concentrations including subspecies, parity and sire. Despite a correlation between embryonic size and placental size, results indicate no significant relationship between PAG concentration and embryo size during early gestation (Pohler et al., 2014). Lack of correlation indicates that the decrease in PAG concentration in cows experiencing late embryonic mortality is indicative of impaired placental or endometrial function, not slow embryonic growth. In addition, Bos indicus cattle tend to have greater circulating PAG concentrations compared to Bos taurus cattle (Pohler et al., 2016b). Any Bos indicus influence in the genetic base will increase PAG concentrations over a straightbred Bos taurus cow (Mercadante et al., 2013). Others have reported that profiles of circulating PAG are similar between subspecies although Bos indicus cows may have a smaller relative increase in the weeks preceding parturition (Sousa et al., 2003). High producing dairy cows exhibit a significant negative correlation between milk production and PAG concentration. In a study by Lopez-Gatius et al. (2007), each $1 \mathrm{~kg}$ increase in milk resulted in a decrease in PAG of 0.08 to $0.1 \mathrm{ng} / \mathrm{ml}$. Perhaps even more interesting are the effects of parity and sire on PAG concentrations. Heifers have consistently been reported to have the greatest PAG concentration and as parity increases, mean PAG concentration subsequently decreased in a somewhat linear fashion until the 3 or 4th parity (Lobago et al., 2009; Ricci et al., 2015; Pohler et al., 2016b). Recent work has examined sire differences on PAG concentration due to the paternal influence over trophoblast and placental development. Preliminary evidence suggests that pregnancies produced by bulls accounting for decreased rates of late EM may exhibit increased PAG concentrations compared to bulls that result in increased rates of late EM (Pohler et al., 2016b).

Estrus expression at the time of insemination or prior to embryo transfer has been directly correlated with pregnancy success in both beef and dairy cattle (Perry et al., 2005; Pereira et al., 2016). In a recent study (Pereira et al., 2016), lactating dairy cows undergoing TAI or embryo transfer had increased fertility and decreased embryonic morality if they exhibited estrus versus those that did not exhibit estrus. Furthermore, lactating dairy cows with pregnancy loss had decreased circulating concentrations of PAGs early in gestation (Pohler et al., 2016a), similar to the current study. In a study with postpartum beef cows, there was an increase in PAG concentrations on day 28 of gestation when comparing estrotech patch scores at TAI (day 0). Surprisingly, previous work has not demonstrated an association with pre/postovulatory estradiol or progesterone production with PAG production early in gestation (Pohler et al., 2013). Thus, these data indicate that cows which exhibit estrus and conceive have increased circulating concentrations of PAGs on d 28 and increased likelihood of pregnancy success compared with pregnant cows that did not express estrus at TAI. Future experiments are needed in this area to truly understand this relationship and potential mechanism that is underlying this increase in PAG production.

\section{Conclusions}

Although numerous detection methods can 
accurately diagnosis pregnancy in cattle, PAGs and pregnancy specific miRNA are biomarkers that can be used before day 30 of gestation and may be useful in predicting embryonic mortality. Although pregnancy diagnosis may be possible earlier in gestation, benefits may be mitigated by high incidence of embryonic mortality after day 24 .

\section{References}

Ahmad N, Schrick FN, Butcher RL, Inskeep EK. 1995. Effect of persistent follicles on early embryonic losses in beef cows. Biol Reprod, 52:1129-1135.

Aires M, Dekagi K, Dantzer V, Yamada A. 2014 Bovine placentome development during early pregnancy. Microscope, 1:390-396.

Athanasas-Platsis S, Quinn $\mathrm{K}$, Wong $\mathrm{T}$, Rolfe B, Cavanagh A, Morton H. 1989. Passive immunization of pregnant mice against early pregnancy factor causes loss of embryonic viability. $J$ Reprod Fertil, 87:495502 .

Ayalon N. 1978. A review of embryonic mortality in cattle. J Reprod Fertil, 54:483-493.

Beal WE, Perry RC, Corah LR. 1992. The use of ultrasound in monitoring reproductive physiology of beef cattle. J Anim Sci, 70:924-929.

Breuel K, Lewis P, Schrick F, Lishman A, Inskeep E, Butcher R. 1993. Factors affecting fertility in the postpartum cow: role of the oocyte and follicle in conception rate. Biol Reprod, 48:655-661.

Burns G, Brooks K, Wildung M, Navakanitworakul R, Christenson LK, Spencer TE. 2014. Extracellular vesicles in luminal fluid of the ovine uterus. PloS One, 9:e90913.

Burns GW, Brooks KE, Spencer TE. 2016. Extracellular vesicles originate from the conceptus and uterus during early pregnancy in sheep. Biol Reprod, 94:1-11.

Butler J, Hamilton W, Sasser R, Ruder C, Hass G, Williams R. 1982. Detection and partial characterization of two bovine pregnancy-specific proteins. Biol Reprod, 26:925-933.

Cameron A, da Silveira JC, Bouma G, Bruemmer JE. 2011. Evaluation of exosomes containing miRNA as an indicator of pregnancy status in the mare. $J$ Equine Vet Sci, 31:314-315.

Cartmill J, El-Zarkouny S, Hensley B, Lamb G, Stevenson J. 2001a. Stage of cycle, incidence, and timing of ovulation, and pregnancy rates in dairy cattle after three timed breeding protocols. $J$ Dairy $S c i$, 84:1051-1059.

Cartmill J, El-Zarkouny S, Hensley B, Rozell T, Smith J, Stevenson J. 2001b. An alternative AI breeding protocol for dairy cows exposed to elevated ambient temperatures before or after calving or both. $J$ Dairy Sci, 84:799-806.

Chim SS, Shing TK, Hung EC, Leung T, Lau T, Chiu RW, Lo. YD. 2008. Detection and characterization of placental microRNAs in maternal plasma. Clin Chem, 54:482-490.

Cordoba M, Sartori R, Fricke P. 2001. Assessment of a commercially available early conception factor (ECF) test for determining pregnancy status of dairy cattle. $J$ Dairy Sci, 84:1884-1889.

Curran S, Pierson R, Ginther O. 1986. Ultrasonographic appearance of the bovine conceptus from days 20 through 60. J Am Vet Med Assoc, 189:1295-1302.

De Vries A. 2006. Economic value of pregnancy in dairy cattle. J Dairy Sci, 89:3876-3885.

Diskin MG, Morris DG. 2008. Embryonic and early foetal losses in cattle and other ruminants. Reprod Domest Anim, 43:260-267.

Diskin MG, Parr M, Morris D. 2011. Embryo death in cattle: an update. Reprod Fertil Dev, 24:244-251.

Dunne L, Diskin M, Sreenan J. 2000. Embryo and foetal loss in beef heifers between day 14 of gestation and full term. Anim Reprod Sci, 58:39-44.

Fiandanese N, Viglino A, Strozzi F, Stella A, Williams JL, Lonergan P, Forde N, Iamartino D. 2016. Circulating microRNAs as potential biomarkers of early pregnancy in high producing dairy cows. In: Proceedings 42nd Annual Meeting of International Embryo Technology Society, 2016, Louisville, KY. Champaign, IL: IETS. (abstract).

Gandy B, Tucker W, Ryan P, Williams A, Tucker A, Moore A, Godfrey R, Willard S. 2001. Evaluation of the early conception factor (ECFTM) test for the detection of nonpregnancy in dairy cattle. Theriogenology, 56:637-647.

Gifford C, Racicot K, Clark D, Austin K, Hansen T, Lucy M, Davies C, Ott T. 2007. Regulation of interferon-stimulated genes in peripheral blood leukocytes in pregnant and bred, nonpregnant dairy cows. J Dairy Sci, 90:274-280.

Gilad S, Meiri E, Yogev Y, Benjamin S, Lebanony D, Yerushalmi N, Benjamin H, Kushnir M, Cholakh H, Melamed N. 2008. Serum microRNAs are promising novel biomarkers. PloS One, 3:e3148.

Green JA, Xie S, Quan X, Bao B, Gan X, Mathialagan N, Beckers JF, Roberts RM. 2000. Pregnancy-associated bovine and ovine glycoproteins exhibit spatially and temporally distinct expression patterns during pregnancy. Biol Reprod, 62:1624-1631.

Green JA, Parks TE, Avalle MP, Telugu BP, McLain AL, Peterson AJ, McMillan W, Mathialagan N, Hook RR, Xie S. 2005. The establishment of an ELISA for the detection of pregnancy-associated glycoproteins (PAGs) in the serum of pregnant cows and heifers. Theriogenology, 63:1481-1503.

Green JC, Okamura C, Poock S, Lucy M. 2010. Measurement of interferon-tau (IFN- $\tau$ ) stimulated gene expression in blood leukocytes for pregnancy diagnosis within 18-20d after insemination in dairy cattle. Anim Reprod Sci, 121:24-33.

Han H, Austin KJ, Rempel LA, Hansen TR. 2006. Low blood ISG15 mRNA and progesterone levels are predictive of non-pregnant dairy cows. $J$ Endocrinol, 191:505-512.

Häusler S, Keller A, Chandran P, Ziegler K, Zipp K, Heuer S, Krockenberger M, Engel J, Hönig A, Scheffler M. 2010. Whole blood-derived miRNA profiles as potential new tools for ovarian cancer screening. British J Cancer, 103:693-700. 
Holdsworth, RJ, Heap RB, Booth JM, Hamon M. 1982. A rapid direct radioimmunoassay for the measurement of oestrone sulphate in the milk of dairy cows and its use in pregnancy diagnosis. $J$ Endocrinol, 95:7-12.

Inskeep EK, Dailey RA. 2005. Embryonic death in cattle. Vet Clin North Am Food Anim Pract, 21:437461.

Ioannidis J, Donadeu X. 2016. Circulating microRNA signatures associated with early bovine pregnancy. In: Proceedings 42nd Annual Meeting of International Embryo Technology Society, 2016, Louisville, KY. Champaign, IL: IETS. (abstract).

Karen A, De Sousa NM, Beckers JF, Bajesy AC, Tibold J, Madl I, Szenci O. 2015. Comparison of a commercial bovine pregnancy-associated glycoprotein ELISA test and a pregnancy-associated glycoprotein radiomimmunoassay test for early pregnancy diagnosis in dairy cattle. Anim Reprod Sci, 159:31-37.

Kastelic J, Curan S, Pierson RA, Ginther OJ. 1988. Ultrasonic evaluation of the bovine conceptus. Theriogenology, 29:39-54.

Kill LK, Pohler KG, Perry GA, Smith MF. 2013. Serum bovine pregnancy associated glycoproteins and progesterone in beef heifers that experienced late embryonic/ fetal mortality. J Anim Sci (Midwest Section Meetings Abstract).

King G, Atkinson B. 1987. The bovine intercaruncular placenta throughout gestation. Anim Reprod Sci, 12:241-254.

King G, Atkinson B, Robertson H. 1979. Development of the bovine placentome during the second month of gestation. J Reprod Fertil, 55:173-180. Kumar A, Mehrotra S, Dangi S, Singh G, Singh L, Mahla A, Kumar S, Nehra K. 2013. Faecal steroid metabolites assay as a non-invasive monitoring of reproductive status in animals. Vet World, 6(1):59-63

Lawrie CH, Gal S, Dunlop HM, Pushkaran B, Liggins AP, Pulford K, Banham AH, Pezzella F, Boultwood J, Wainscoat JS. 2008. Detection of elevated levels of tumour-associated microRNAs in serum of patients with diffuse large B-cell lymphoma. Br J Haematol, 141:672-675.

Lobago F, Bekana M, Gustafsson H, Beckers JF, Yohannes G, Aster Y, Kindahl H. 2009. Serum profiles of pregnancy-associated glycoprotein, oestrone sulphate and progesterone during gestation and some factors influencing the profiles in ethiopian Borana and crossbred cattle. Reprod Domest Anim, 44:685-692.

Lopez-Gatius F, Garbayo J, Santolaria P, Yaniz J, Ayad A, De Sousa N, Beckers JF. 2007. Milk production correlates negatively with plasma levels of pregnancy-associated glycoprotein (PAG) during the early fetal period in high producing dairy cows with live fetuses. Domest Anim Endocrinol, 32:29-42.

Lucy M, Green J, Poock S. 2011. Pregnancy determination in cattle: a review of available alternatives. In: Proceedings, Applied Reproductive Strategies in Beef Cattle, Joplin, MO. Lincoln, NE: University of Nebraska-Lincoln. pp. 367-376.

Mercadante PM, Waters KM, Mercadante VR, Lamb GC, Elzo MA, Johnson SE, Rae DO, Yelich
JV, Ealy AD. 2013. Subspecies differences in early fetal development and plasma pregnancy-associated glycoprotein concentrations in cattle. $J$ Anim Sci, 91:3693-3701.

Morton H. 1998. Early pregnancy factor: an extracellular chaperonin 10 homologue. Immun Cell Biol, 76:483-496.

Nebel R, Whittier W, Cassell B, Britt J. 1987. Comparison of on-farm and laboratory milk progesterone assays for identifying errors in detection of estrus and diagnosis of pregnancy. J Dairy Sci, 70:14711476.

Nebel R. 1988. On-farm milk progesterone tests. $J$ Dairy Sci, 71:1682-1690.

Pereira M, Wiltbank M, Vasconcelos J. 2016. Expression of estrus improves fertility and decreases pregnancy losses in lactating dairy cows that receive artificial insemination or embryo transfer. J Dairy Sci, 99:2237-2247.

Perry GA, Smith MF, Lucy MC, Green JA, Parks TE, MacNeil MD, Roberts AJ, Geary TW. 2005. Relationship between follicle size at insemination and pregnancy success. Proc Nat Acad Sci USA, 102:52685273.

Pierson RA, Ginther OJ. 1984. Ultrasonography for detection of pregnancy and study of embryonic development in heifers. Theriogenology, 22:225-233.

Pohler KG, Geary TW, Johnson CL, Atkins JA, Jinks EM, Busch DC, Green JA, MacNeil MD, Smith MF. 2013. Circulating bovine pregnancy associated glycoproteins are associated with late embryonic/fetal survival but not ovulatory follicle size in suckled beef cows. J Anim Sci, 91:4158-4167.

Pohler KG, Green JA, Moley LA, Doran KM, Graff HB, Peres RFG, Vasconcelos JLM, Smith MF. 2014. The effect of embryonic size and sire on circulating concentrations of bovine pregnancy associated glycoproteins in beef cattle. In: Juengel J, Miyamoto A, Price C, Reynolds L, Smith M, Webb R (Ed.). International Symposium on Reproduction in Domestic Ruminants. Obihiro, Hokkaido: Context. pp. 563

Pohler KG, Green JA, Geary TW, Peres RF, Pereira MH, Vasconcelos JL, Smith MF. 2015a. Predicting embryo presence and viability. Adv Anat Embryo Cell Biol, 216:253-270.

Pohler KG, Green JA, Moley LA, Hung W, Hong X, Christenson LK, Geary TW, Smith MF. 2015b. Circulating microRNAs as biomarkers of early embryonic viability in cattle. In: Proceedings Society for the Study of Reproduction Annual Meeting, 2015, San Juan, Puerto Rico. Madison, WI: SSR. (abstract).

Pohler KG, Pereira MH, Lopes FR, Lawrence JC, Keisler DH, Smith MF, Vasconcelos JL, Green JA. 2016a. Circulating concentrations of bovine pregnancyassociated glycoproteins and late embryonic mortality in lactating dairy herds. J Dairy Sci, 99:1584-1594.

Pohler KG, Peres RF, Green JA, Graff HB, Martins T, Vasconcelos JL, Smith MF. 2016b. Use of bovine pregnancy associated glycoproteins (bPAGs) to diagnose pregnancy and predict late embryonic mortality in postpartum Nelore beef cows. Theriogenology, 85:1652-1659. 
Raposo G, Stoorvogel W. 2013. Extracellular vesicles: exosomes, microvesicles, and friends. $J$ Cell Biol, 200:373-383.

Reese ST, Pereira MHC, Vasconcelos JLM, Pohler KG. 2016. Pregnancy associated glycoprotein (PAG) concentrations in early gestation from dairy heifers undergoing embryo transfer. In: Proceedings ASASADAS Joint Annual Meeting, 2016, Salt Lake City, Utah. Champaign, IL: ASAS, ADAS. (abstract).

Reid G, Kirschner MB, van Zandwijk N. 2011 Circulating microRNAs: Association with disease and potential use as biomarkers. Crit Rev Oncol Hematol, 80:193-208.

Ricci A, Carvalho P, Amundson M, Fourdraine R, Vincenti L, Fricke P. 2015. Factors associated with pregnancy-associated glycoprotein (PAG) levels in plasma and milk of Holstein cows during early pregnancy and their effect on the accuracy of pregnancy diagnosis. J Dairy Sci, 98:2502-2514.

Santos J, Thatcher W, Chebel R, Cerri R, Galvao K. 2004. The effect of embryonic death rates in cattle on the efficacy of estrus synchronization programs. Anim Reprod Sci, 82:513-535.

Santos J, Rutigliano H, Sá Filho M. 2009. Risk factors for resumption of postpartum estrous cycles and embryonic survival in lactating dairy cows. Anim Reprod Sci, 110:207-221.

Sartori R, Sartor-Bergfelt R, Mertens S, Guenther J, Parrish J, Wiltbank M. 2002. Fertilization and early embryonic development in heifers and lactating cows in summer and lactating and dry cows in winter. $J$ Dairy Sci, 85:2803-2812.

Sasser R. 1987. Detection of early pregnancy in domestic ruminants. J Reprod Fertil Suppl, 34:216-271.

Sasser RG, Ruder CA, Ivani KA, Butler JE, Hamilton WC. 1986. Detection of pregnancy by radioimmunoassay of a novel pregnancy-specific protein in serum of cows and a profile of serum concentrations during gestation. Biol Reprod, 35:936942.

Sousa NM, Zongo M, Pitala W, Boly H, Sawadogo L, Sanon M, Figueiredo JR, Gonçalves PBD, El Amiri B, Perènyi Z. 2003. Pregnancy-associated glycoprotein concentrations during pregnancy and the postpartum period in Azawak Zebu cattle. Theriogenology, 59:1131-1142.
Spencer TE, Hansen TR. 2015. Implantation and establishment of pregnancy in ruminants. In: Geisert RD, Bazer FW. (Ed.). Regulation of Implantation and Establishment of Pregnancy in Mammal. New York, NY: Springer. pp. 105-135.

Sreenan J, Diskin M. 1986. The extent and timing of embryonic mortality in the cow. Embryonic mortality in farm animals. New York, NY: Springer pp. 1-11.

Starbuck MJ, Dailey RA, Inskeep EK. 2004. Factors affecting retention of early pregnancy in dairy cattle. Anim Reprod Sci, 84:27-39.

Szenci O, Beckers JF, Humblot P, Sulon J, Sasser G, Taverne M, Varga J, Baltusen R, Schekk G. 1998. Comparison of ultrasonography, bovine pregnancyspecific protein $\mathrm{B}$, and bovine pregnancy-associated glycoprotein 1 tests for pregnancy detection in dairy cows. Theriogenology, 50:77-88.

Tijsen AJ, Creemers EE, Moerland PD, de Windt LJ, van der Wal AC, Kok WE, Pinto YM. 2010. MiR423-5p as a circulating biomarker for heart failure. Circ Res, 106:1035-1039.

United States Department of Agriculture. 2009. NAHMS Dairy 2007. Washington, DC: USDA APHIS.

United States Department of Agriculture. 2010. NAHMS Beef 2007-2008. Washington, DC: USDA APHIS.

Wallace RM, Pohler KG, Smith MF, Green JA. 2015. Placental PAGs: gene origins, expression patterns, and use as markers of pregnancy. Reproduction, 149:R115-126.

Wang J, Yu M, Yu G, Bian J, Deng X, Wan X, Zhu K. 2010. Serum miR-146a and miR-223 as potential new biomarkers for sepsis. Biochem Biophys Commun, 394:184-188.

Wooding F, Wathes DC. 1980. Binucleate cell migration in the bovine placentome. J Reprod Fertil, 59:425-430.

Wooding P, Burton G. 2008. Synepitheliochorial placentation: ruminants (ewe and cow). Comparative Placentation: Structures, Functions and Evolution. New York, NY: Springer. pp. 133-167.

Zoli AP, Guilbault LA, Delahaut P, Ortiz WB, Beckers JF. 1992. Radioimmunoassay of a bovine pregnancy-associated glycoprotein in serum: its application for pregnancy diagnosis. Biol Reprod, 46:83-92. 